\title{
Simulation Of The PV Array Output Characteristic In Shading
}

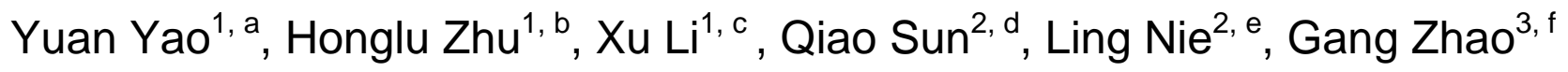 \\ ${ }^{1}$ State Key Laboratory of Alternate Electrical Power System with Renewable Energy Sources, North \\ China Electric Power University, Beijing 102206, China; \\ ${ }^{2}$ Guodiantong Network Technology Co., Beijing 100070, China; \\ ${ }^{3}$ School of Electronic Engineering, Xidian University, Xian 710071, China. \\ ayaoyuan_ncepu@126.com, ${ }^{\mathrm{b}}$ hongluzhu@126.com, ${ }^{\mathrm{c}}$ lixu_ncepu@126.com, ${ }^{\mathrm{d}}$ \\ sunqiao@sgepri.sgcc.com.cn, ${ }^{\mathrm{e}}$ nieling@sgepri.sgcc.com.cn, ${ }^{\mathrm{f}}$ gangzhao@mail.xidian.edu.cn
}

Keywords: PV, model, the maximum power point, location distribution

\begin{abstract}
PV nonlinear characteristics caused by complex external environment and the complexity of PV maximum power point locations distribution influence the design and optimization of photovoltaic maximum power tracking algorithm. Based on PV equivalent circuit model, unknown parameters of PV model are solved by an iterative algorithm. And then, a mathematical model of the PV array full of working conditions are built. Typical shading and external environmental conditions are designed, then distance analysis method are used to study the distribution of PV maximum power point. Simulation results show that the voltage of PV maximum power point mainly affected by temperature and uneven lighting conditions will affect the number of maximum power point of PV.
\end{abstract}

\section{Introduction}

Since solar energy is sustainable, widely distributed, no pollution and no noise [1]. PV proportion in the modern energy structure system is growing. However, PV array has low efficiency when external environment and load are changing [2]. To ensure optimal use of the available solar energy, maximum power point tracking (MPPT) scheme is applied to the power converters [3]. The mathematical model of the photovoltaic device is significantly valuable for studying the maximum power point tracking algorithms [4]. Over the years, several researchers have studied PV output characteristics and Accurate modeling of PV. Furthermore, they focus on Optimizing MPPT algorithm by simulation to improve the efficiency of photovoltaic systems. However, there are two problems: Ideal Illuminations which used in simulation usually can't reflect the actual lighting conditions [5]. The characteristics get more complicated if the entire array does not receive uniform insolation resulting in multiple peaks. The presence of multiple peaks reduces the effectiveness of the existing maximum power point tracking [6]. Secondly, modeling of the PV array depends on the equivalent circuit model. Model series and parallel resistance set by experience will bring great error [7]. Also, current researches lack of the summary of the position of the maximum power point of distribution.

Therefore, this article proposes to calculate PV equivalent circuit series and parallel resistance parameters using an iterative method and establish a comprehensive mathematical model of PV array. And then design the experiment of output characteristics of the photovoltaic in shading and generalize distribution of PV maximum power point. Finally, make a suggestion of the design and optimization of maximum power point tracking algorithm.

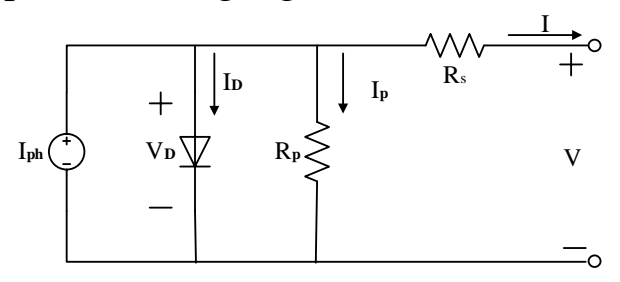

Fig. 1 Photovoltaic cell equivalent model 


\section{PV module modeling}

\section{Mathematical model of PV modules and arrays.}

Photovoltaic cell equivalent model are shown in Figure 1. The model consists of four parts: $I_{p h}$ is the current generated by the incidence of light; Diode D, describe the movement of the internal P-N junction of PV cell; Shunt resistor $R_{p}$, a photovoltaic cell is mainly caused by leakage current; Series resistance $R_{s}$, mainly consist of the internal resistance of the battery and the metal conductor resistance.

$$
I=I_{p h}-I_{d}-I_{p}
$$

Where $I$ is the PV cell output current; $I_{p h}$ is the photocurrent, $I_{d}$ is the diode current; $I_{p}$ is the shunt resistor current.

A modified equation for the current for PV array with $N_{s}$ PV cell:

$$
I=I_{p h}-I_{0}\left[\exp \left(\frac{V+I R_{s}}{a}\right)-1\right]-\frac{V+I R_{s}}{R_{p}}
$$

Where ' $a$ ' is the modified ideality factor.

$$
a=\frac{N_{s} \cdot A \cdot k \cdot T_{C}}{q}=N_{s} \cdot A \cdot V_{T}
$$

\section{Determination of $R_{p}$ and $R_{s}$ values.}

The expression for $R_{p}$ at maximum power point can be rearranged and rewritten as

$$
R_{p}=\frac{V_{m}+I_{m} R_{s}}{I_{p h}-I_{0}\left[\exp \left(\frac{V+I_{m} R_{s}}{a}\right)-1\right]-I_{m}}
$$

When $R_{s}$ is given, $R_{p}$ can be calculated easily. Therefore, by taking the advantage of this algebraic expression, a simple and linear iterative method can be adopted. Set initial $R_{s}$ values and calculate corresponding $R_{p}$.Secondly, increase the value of $R_{s}$, while simultaneously calculating the $R_{p}$ value. Then, calculated peak power ( $\left.P_{m, C}\right)$ and the experimental (from manufacturer's datasheet) peak power ( $P_{m, E}$ ). The initial value of $R_{s}$ is chosen to be zero, and the initial value of $R_{p}$ can be calculated by the following equation:

$$
R_{p 0}=\left(\frac{V_{m}}{I_{s c}-I_{m}}\right)-\left(\frac{V_{o c}-V_{m}}{I_{m}}\right)
$$

For a typical PV model, the difference between $V_{o c}$ and $V_{m}$ isn't large, so the value of the second part of this equation is low. Also, the first part of the equation are less than the real value of $R_{p}$.So $R_{p 0}$ calculated by equation (5) is a good initial value for the iteration.

\section{Simulation design in shading condition}

To better illustrate the various shelter of the output characteristics of the PV array in shading and the distribution of the maximum power point position, this paper set six kind of shading conditions shown in Figure 2. 


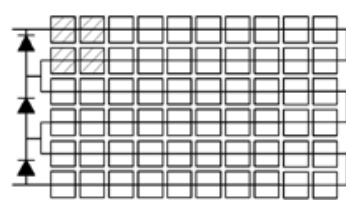

(a)Type 1

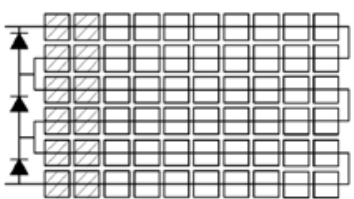

(d) Type 4

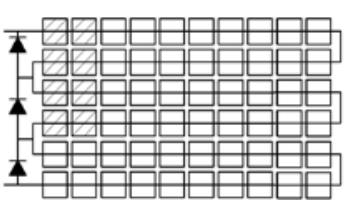

(b) Type 2

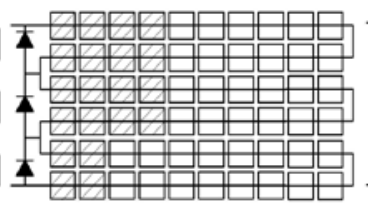

(e) Type 5

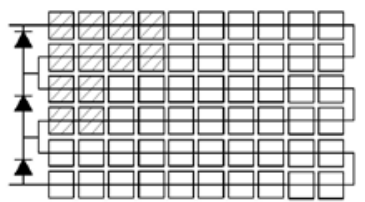

(c) Type 3

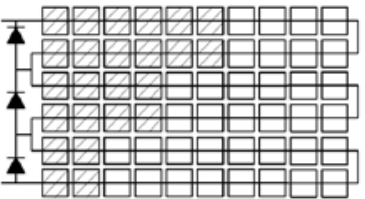

(f) Type 6

Fig. 2 Shading conditions

Figure 3,4,5 describe the distribution of the maximum power point and the output characteristics of the photovoltaic in type1,3,4 respectively. PV array power characteristic curve has multiple peaks. Since the shadow falls on one or two components, the number of maximum power point respectively two and three.

Voltage distance $\Delta U_{\text {STC,con }}$ and current distance $\Delta I_{\text {STC,con }}$ are used to further illustrate the distribution of maximum power point in various conditions.

$$
\begin{gathered}
\Delta U_{S T C, \text { con }}=\frac{a b s\left(U_{S T C}-U_{c o n}\right)}{U_{S T C}} \\
\Delta I_{S T C, \text { con }}=\frac{a b s\left(I_{S T C}-I_{c o n}\right)}{I_{S T C}}
\end{gathered}
$$

Where $\Delta U_{\text {STC,con }}$ and $\Delta I_{\text {STC,con }}$ are the distance from the voltage and current of maximum power point in STC to the it in operation condition respectively. STC is the standard test condition: Irradiance is $1000 \mathrm{~W} / \mathrm{m}^{2}$; Temperature is $25 \pm 1{ }^{\circ} \mathrm{C}$; Spectral characteristics: AM1.5 standard spectrum.

Table 1 shows the parameters and characteristics of PV array in shading. Short-circuit current is advanced with the growth of irradiance while open-circuit voltage is substantially stable in constant temperature; Open-circuit voltage is reduced with the growth of temperature while Short-circuit current is substantially stable in constant irradiance. The position of the maximum power point along the voltage axis changes mainly due to the change of temperature; The position of the maximum power point along the power axis changes mainly due to the change of irradiance. The output power of the array becomes smaller when some components in the shadows, then the location of maximum power point of the array below the STC condition without shadows. When some components in the shadows, the position of the maximum power point voltage near $\Delta U_{\text {STC,con }}$.

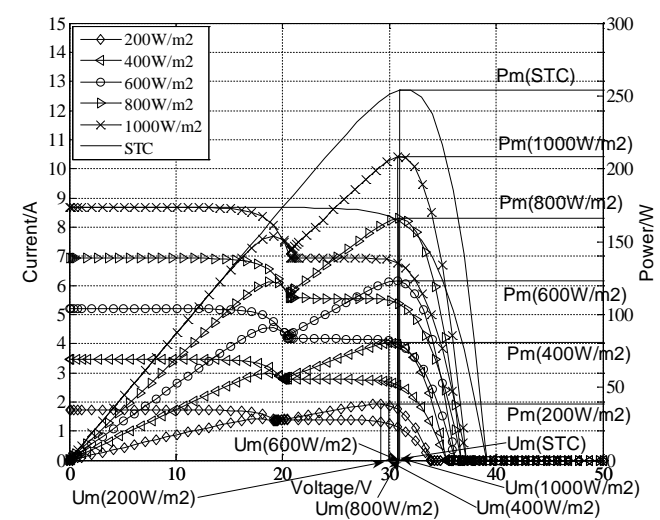

(a) $25^{\circ} \mathrm{C}$, different irradiance

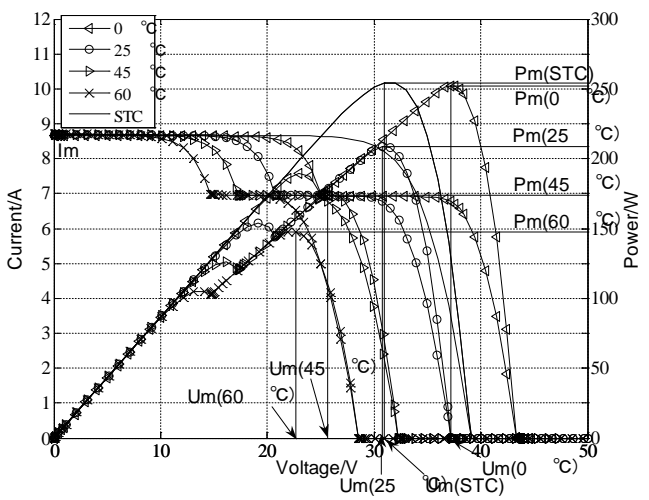

(b) $1000 \mathrm{~W} / \mathrm{m}^{2}$, different temperature

Fig. 3 Output characteristics of PV modules in type 1 


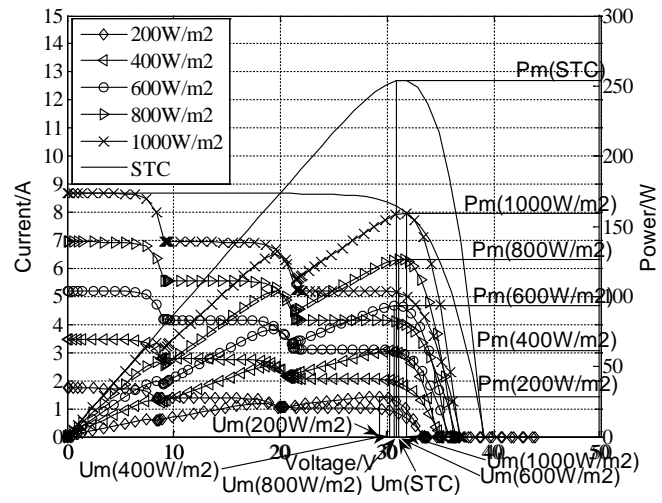

(a) $25^{\circ} \mathrm{C}$, different irradiance

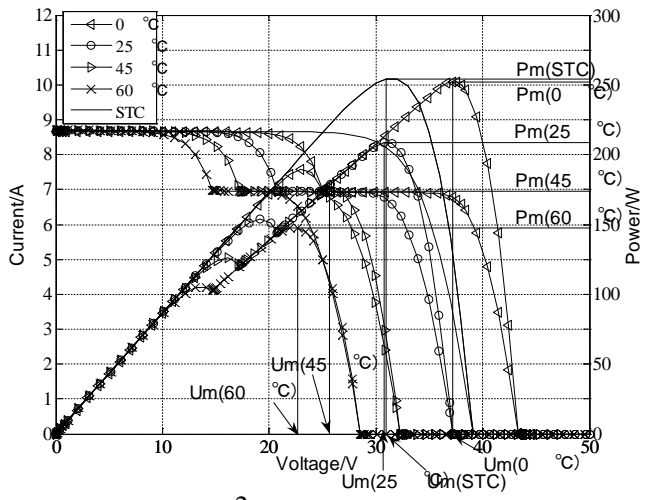

(b) $1000 \mathrm{~W} / \mathrm{m}^{2}$, different temperature

Fig. 4 Output characteristics of PV modules in type 1

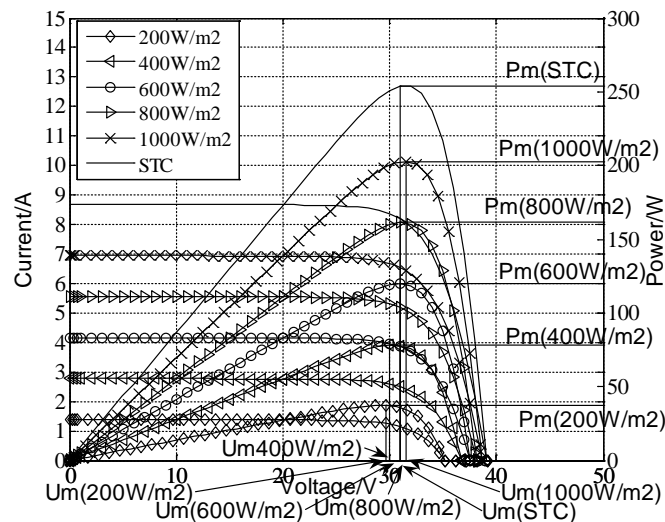

(a) $25^{\circ} \mathrm{C}$, different irradiance

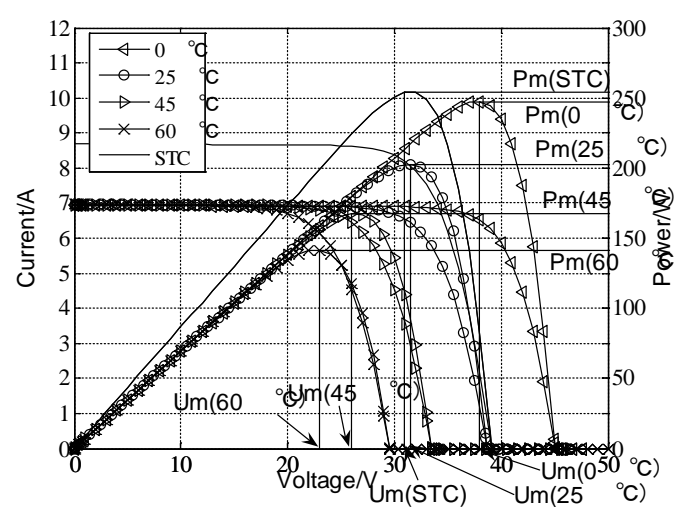

(b) $1000 \mathrm{~W} / \mathrm{m}^{2}$, different temperature

Fig. 5 Output characteristics of PV modules in type 1

Table $1 \mathrm{PV}$ array properties in different conditions

\begin{tabular}{|c|c|c|c|c|c|}
\hline $\begin{array}{l}\text { Shadow } \\
\text { type }\end{array}$ & Restrictions & $\Delta U_{\text {STC, con }}$ & $\Delta I_{\mathrm{STC}, \mathrm{con}}$ & $\begin{array}{c}\text { Maximum Power Point } \\
\text { Properties }\end{array}$ & $\begin{array}{l}\text { The number of } \\
\text { maximum power } \\
\text { point }\end{array}$ \\
\hline 1 & $\begin{array}{l}\text { Constant temperature, } \\
\text { Various irradiance }\end{array}$ & Low & High & $\begin{array}{l}\text { Lower than STC, voltage } \\
\text { stability }\end{array}$ & 2 \\
\hline 1 & $\begin{array}{l}\text { Constant irradiance, } \\
\text { Various irradiance }\end{array}$ & High & Low & $\begin{array}{c}\text { Lower than STC,MPPT } \\
\text { move left with the reduce of } \\
\mathrm{T}\end{array}$ & 2 \\
\hline 2 & $\begin{array}{l}\text { Constant temperature, } \\
\text { Various irradiance }\end{array}$ & Low & High & $\begin{array}{l}\text { Lower than STC, voltage } \\
\text { stability }\end{array}$ & 3 \\
\hline 2 & $\begin{array}{l}\text { Constant irradiance, } \\
\text { Various irradiance }\end{array}$ & High & Low & $\begin{array}{c}\text { Lower than STC,MPPT } \\
\text { move left with the reduce of } \\
\text { T }\end{array}$ & 3 \\
\hline 3 & $\begin{array}{l}\text { Constant temperature, } \\
\text { Various irradiance }\end{array}$ & Low & High & $\begin{array}{l}\text { Lower than STC, voltage } \\
\text { stability }\end{array}$ & 1 \\
\hline 3 & $\begin{array}{l}\text { Constant irradiance, } \\
\text { Various irradiance }\end{array}$ & High & Low & $\begin{array}{c}\text { Lower than STC,MPPT } \\
\text { move left with the reduce of } \\
\text { T }\end{array}$ & 1 \\
\hline
\end{tabular}

\section{Summary}

In this paper,a comprehensive mathematical model of PV array is established and design a iterative calculation for $R_{s}$ and $R_{p}$.To illustrate the positional distribution of PV maximum power point, design a experiment of output characteristics of the PV array in typically shading. Simulation results show the following important features of PV maximum power point locations distribution: 
Voltage position near the STC maximum power point voltage when there some components in shading. So the initial value of MPPT algorithm can set to the value near $U_{\text {STC }}$; Simulation results show that the voltage of PV maximum power point mainly affected by temperature. Therefore, the maximum power point tracking algorithm design should consider amending temperature.The difference between the MPP location in shading and unshaded is small.So,the location of MPP in shading can be calculated by the location of MPP without shading.

\section{Acknowledgments}

The authors would like to acknowledge the financial support of the Beijing Higher Education Young Elite Teacher Project (YETP0714), the Program of the Co-Construction with Beijing Municipal Commission of Education, State Key Laboratory of Alternate Electrical Power System with Renewable Energy Sources (LAPS14006).

\section{References}

[1]. Alian Chen, Lina Feng, Chunshui Du, et al. Modeling of photovoltaic Array Based on Support Vector Machines Under Partial Shaded Conditions. Transactions of China Electrotechnical Society.Vol. 26(2011) No. 3, p. 140-146.

[2]. Wenbao Hou, Yonghui Zhao. The Research of MPPT based on Variable Step Size Incremental Conductance Method. Electronics World. Vol. 2(2013) , p. 26-27.

[3]. A Chaouachi, RM Kamel, K Nagasaka. A novel multi-model neurofuzzy-based MPPT for three-phase grid-connected photovoltaic system. Solar Energy. Vol. 84(2010) No. 12, p. 2219-2229.

[4]. M Seyedmahmoudian, S Mekhilef, R Rahmani, et al. Analytical Modeling of Partially Shaded Photovoltaic Systems.Energies, Vol. 6(2013) No. 1, p.128-144.

[5]. Jingliang Xiao, Zheng $\mathrm{Xu}$, Chong Lin, et al. Optimal Design of Photovoltaic Arrays Under Partial Shading. Proceedings of the CSEE. Vol. 29(2009)No. 11, p. 119-124.

[6]. Patel H, Agarwal V. Matlab-based modeling to study the effects of partial shading on PV array characteristics. IEEE Trans on Energy Conversion, Vol. 23(2008)No. 1, p. 302-310.

[7]. K.Ishaque, Z.Salam, Syafaruddin, A comprehensive MATLAB Simulink PV system simulator with partial shading capability based on two-diode model. Solar Energy. Vol. 82(2011)No. 9, p. 2217-2227. 